九州大学学術情報リポジトリ

Kyushu University Institutional Repository

\title{
Deriving the Storage Function Model Parameters by Using Runoff Data Only
}

Sujono, Joko

Laboratory of Drainage and Water Environment, Division of Regional Environment Science, Department of Bioproduction Environmental Science, Graduate School of Bioresource and Bioenvironmental Sciences, Kyushu University

Shikasho, Shiomi

Laboratory of Drainage and Water Environment, Division of Regional Environment Science, Department of Bioproduction Environmental Science, Faculty of Agriculture, Kyushu University

Hiramatsu, Kazuaki

Laboratory of Drainage and Water Environment, Division of Regional Environment Science,

Department of Bioproduction Environmental Science, Faculty of Agriculture, Kyushu University

https://doi.org/10.5109/24466

出版情報: 九州大学大学院農学研究院紀要. 47 (1)，pp.129-138，2002-10-30. Kyushu University バージョン：

権利関係 : 


\title{
Deriving the Storage Function Model Parameters by Using Runoff Data Only
}

\author{
Joko SUJONO*, Shiomi SHIKASHO and Kazuaki HIRAMATSU \\ Laboratory of Drainage and Water Environment, Division of Regional Environment Science, \\ Department of Bioproduction Environmental Science, Faculty of Agriculture, \\ Kyushu University, Fukuoka 812-8581, Japan \\ (Received June 13, 2002 and accepted July 12, 2002)
}

\begin{abstract}
Rainfall-runoff models require rainfall and runoff data for determining the model parameters. Problem usually emerges in finding the optimal model parameters due to lack of rainfall data in terms of quantity and quality. In a lumped model such as the storage function model, good quality and quantity of input (rainfall) data that represent the catchment behavior is needed in order to get the optimum model parameters. However, it is difficult to get the rainfall data that fulfill the requirement as results of high spatial variability of rainfall data and lack of automatic rainfall recorder that are commonly found in tropical regions.

To overcome the above problem, the filter separation autoregressive model might be used to estimate the rainfall time series based on runoff data only. The resulted rainfall together with the runoff data are then used to find the storage function model parameters. The results show that the inversely estimated rainfall was useful for estimating the rainfall-runoff model parameters in topical regions.
\end{abstract}

\section{INTRODUCTION}

A number of conceptual rainfall runoff models using storage-discharge relationships have been developed and applied. One of the most widely used such kind of model for runoff analysis in Japan is the storage function model (SFM) developed by Kimura (1961). Since then, some studies have been carried out to analyze the model parameter characteristics (Sugiyama et al., 1997; 1999).

The SFM, as a lumped model, requires a good quality and quantity of input (rainfall) data that represent the catchment behavior for getting the optimum model parameters. In practice, however, it is quite difficult to get rainfall data that fulfill the requirement as results of high spatial variability of rainfall data and lack of automatic rainfall recorder that are usually found in tropical regions.

To overcome the observed rainfall data problem, synthetic rainfall data might be generated and then used for the model calibration. Hino and Hasebe $(1981 ; 1984)$ proposed a method for estimating effective rainfall for each flow component and showed that as a whole the sum of each inversely estimated rainfall component compare relatively well with the observed ones. The rainfall component for each flow component is estimated sequentially by fitting to the ARX model (auto-regressive model with exogenous input)

\footnotetext{
* Laboratory of Drainage and Water Environment, Division of Regional Environment Science, Department of Bioproduction Environmental Science, Graduate School of Bioresource and Bioenvironmental Sciences, Kyushu University.

* Corresponding author (E-mail: jsujono@agr.kyushu-u.ac.jp)
} 
(Hino and Hasebe, 1984). The runoff components i.e. surface-interflow (direct flow) component and groundwater flow or baseflow component are obtained from raw runoff time series data through a numerical separation filter.

In this paper, the filter separation autoregressive method (Hino and Hasebe, 1984) is used to estimate the effective rainfall time series for direct flow component. The estimated rainfall time series together with the direct flow component are then used to find the SFM parameters.

\section{IDENTIFICATION OF THE STORAGE FUNCTION MODEL PARAMETERS}

Parameter identification of the storage function model (SFM) is based on the fuzzy regression model (Shikasho et al., 1992). The basic equations of the SFM are as follows:

$$
S_{l}=K Q^{P},
$$

and

$$
S_{l}=\int_{0}^{t-T} r_{e} d t-\int_{0}^{t} Q d t
$$

where $S_{l}$ is the storage depth of rain-water (mm) over the catchment accounting for the lag time $T_{i}(\mathrm{~h})$ between the rainfall excess $r_{i}(\mathrm{~mm} / \mathrm{h})$ and the flood runoff depth $Q$ $(\mathrm{mm} / \mathrm{h})$, whereas $t$ is time (h). $K, P$, and $T_{1}$ are the model parameters. Equation (2) can be rewritten as:

$$
\begin{aligned}
S_{l} & =-\int_{t-T_{l}}^{t} r_{e} d t+\int_{0}^{t} r_{e} d t-\int_{0}^{t} Q d t \\
& =-\int_{t-T_{l}}^{t} r_{e} d t+S .
\end{aligned}
$$

By combining (1) and (3), $S$ can be expressed as:

$$
S=\int_{t=T}^{l} r_{e} d t+K Q^{p}
$$

Suppose,

$$
\begin{aligned}
\int_{t-T_{l}}^{t} r_{e} d t & =r_{0} T_{l}, \\
K Q^{P} & =K_{0} Q^{P_{0}}+\frac{\partial K Q^{P}}{\partial K}\left(K-K_{0}\right)+\frac{\partial K Q^{P}}{\partial P}\left(P-P_{0}\right) \\
& =Q^{P_{0}} K+K_{0} Q^{P_{0}} \ln (Q) P-K_{0} P_{0} Q^{P_{0}} \ln (Q),
\end{aligned}
$$

hence,

$$
S=r_{0} T_{l}+Q^{P_{0}} K+K_{0} Q^{P_{0}} \ln (Q) P-K_{0} P_{0} Q^{P_{0}} \ln (Q),
$$

where $r_{0}$ is average effective rainfall intensity between $t-T_{l}$ and $t$. By using the fuzzy linear regression (FLR) (Tanaka et al., 1982) and by introducing fuzzy parameters into the SFM parameters: $K=\left(\alpha_{K}, c_{K}\right), P=\left(\alpha_{P}, c_{P}\right), T_{l}=\left(\alpha_{T_{i}}, c_{T_{l}}\right)$, the FLR equations of the SFM (5) can be obtained as:

$$
\begin{aligned}
& r_{0} \alpha_{T_{i}}+Q_{2}^{P_{0}} \alpha_{K}+K_{0} Q_{i}^{P_{0}} \ln \left(Q_{i}\right) \alpha_{p}+ \\
& \quad(1-h)\left(r_{0} C_{T_{i}}+Q_{i}^{P_{0}} C_{K}+K_{0} Q_{i}^{P_{0}}\left|\ln \left(Q_{i}\right)\right| c_{P}\right) \geq S_{i}+K_{0} P_{0} Q_{i}^{P_{0}} \ln \left(Q_{i}\right)
\end{aligned}
$$




$$
\begin{aligned}
& r_{\theta} \alpha_{T_{i}}+Q_{i}^{P_{0}} \alpha_{K}+K_{0} Q_{i}^{P_{0}} \ln \left(Q_{i}\right) \alpha_{P}- \\
& \quad(1-h)\left(r_{0} c_{T_{i}}+Q_{i}^{P^{0}} C_{K}+K_{0} Q_{i}^{P_{0}}\left|\ln \left(Q_{i}\right)\right| c_{P}\right) \leq S_{i}+K_{0} P_{0} Q_{i}^{P_{0}} \ln \left(Q_{i}\right) \\
& \alpha_{7 l} \alpha_{K}, \alpha_{P}, c_{T_{i}}, c_{K}, c_{P}, \geq 0
\end{aligned}
$$

where $h$ is a threshold level describing the reliability of the data whereas $\alpha, c$ are the center and the width of the fuzzy set, respectively. The $h$ level is in the range of $0 \leq h<1$ in which $h=0$ represents the most reliable data. Those equations can be solved using linear programming by minimizing the vagueness of the FLR model that is the sum of all the widths of the fuzzy parameters as follows:

$$
\sum\left(r_{0} c_{T_{l}}+Q_{i}^{P_{0}} C_{K}+K_{0} Q_{i}^{p_{0}}\left|\ln \left(Q_{i}\right)\right| c_{P}\right) \rightarrow \min (i=1,2 \cdots, n) .
$$

\section{FILTER SEPARATION AUTOREGRESSIVE MODEL}

Hino and Hasebe $(1981,1984)$ proposed a technique for estimating effective rainfall time series of a catchment by using the filter separation autoregressive method. The method is based on the output of the catchment i.e. runoff data only. It implies that the effect of spatial variability of rainfall and the initial soil moisture condition have been incorporated in the method. To get the inversely estimated rainfall of each flow component from the raw runoff data, some steps have to be followed i.e.: determination of cut-off frequency, separation of a flood event into its components, calculating the autoregressive values of each flow component and followed by rainfall time series estimation.

\section{Determination of Cut-Off Frequency}

In the hourly flood hydrograph data, the rainfall as the input of the catchment system is active only for the first part of the hydrograph data. After cessation of rainfall, the system is driven only by a noise with a very low level compare to rainfall (Hino and Hasebe, 1984). As a result, the recession curve of the flood hydrograph data may be used to determine the cut-off frequency of the component separation of hourly hydrologic data.

The cut-off frequency can be determined by using semi-logarithmic plots of the recession hydrograph by determining the slope of the recession curve. However, this graphical method is very subjective. Hence, determining the cut-off frequency will be carried out by using wavelet transforms approach that gives an objective result (Sujono $e t$ al., 2001).

\section{Separation of a Flood Event into its Components}

Separation of a flood event data into its flow components can be carried out by using numerical filtering of the data that may be calculated using (Hino and Hasebe, 1984):

$$
h(\tau)= \begin{cases}\left.c_{0} \exp \left(-\frac{1}{2} c_{1} \tau\right) \sinh \left[\frac{1}{4} c_{1}{ }^{2}-c_{0}\right)^{\frac{1}{2}} \tau\right] /\left(\frac{1}{4} c_{1}{ }^{2}-c_{0}\right)^{\frac{1}{2}}, & \tau \geq 0 \\ 0, & \tau<0\end{cases}
$$

The numerical filter $h(\tau)$ contains two parameters $c_{0}$ and $c_{1}$ that can be calculated from:

$$
c_{0}=\left(\delta / T_{c}\right)^{2} \text { and } c_{1}=\delta^{2} / T_{c}
$$


where $\delta$ is a damping factor $(\delta>2), T_{c}=1 / f_{c}^{\prime}$ in which $f_{c}^{\prime}$ is a cut-off frequency.

As the cut-off parameters $c_{0}$ and $c_{1}$ are determined, the observed flood data are separated into its flow components, generally it consists of groundwater flow and surface-interflow components, using the following equation:

$$
q^{(1)}(t)=\alpha \sum w_{k} q(t-k)
$$

in which, $w_{k}=h(k \Delta t),(k=0,1,2, \ldots, N), \Delta t$ is a unit time interval $(1 h), q^{(1)}(t)$ is the filtered groundwater flow and $\alpha$ is a weighting factor should be chosen so that the filtered groundwater flow and residual outputs $q^{(2)}(t)$ should not be negative. Hence, the surface-interflow component $q^{(2)}(t)$ is calculated by:

$$
q^{(2)}(t)=q(t)-q^{(1)}(t),
$$

where $q(t)$ is actual flow. Since raw flood data is usually consists of actual flow resulted from its concurrent rainfall and initial flow due to previous rainfall, the later flow should be subtracted from the raw flood data before applying the numerical separation filter method. In this study, the initial flow is assumed equal to a minimum discharge value at the beginning of the selected flood event and it is taken constant during the time.

\section{Determination of Rainfall Time Series}

The rainfall-runoff process may be fitted by an ARX model with the input (rainfall) $\hat{r}_{i}^{(l)}$ for the $l$ th component, where $l=1,2$ correspond to groundwater flow component and direct flow component, respectively. The hourly runoff $q_{i}^{\left({ }^{(l)}\right.}$ is described by (Hino, 1986):

$$
q_{2}^{(l)}=a_{1}^{(l)} q_{i-1}^{(l)}+a_{2}^{(l)} q_{i-2}^{(l)}+\cdots+a_{p}^{(l)} q_{i p}^{(l)}+\lambda b^{(i)} \hat{r}_{i^{\prime}}^{(l)}+\varepsilon_{i}^{(l)}
$$

where $a_{i}{ }^{(l)}$ are autoregressive coefficients that could be computed using the Yule-Walker or Burg algorithms, $b^{(l)}$ is a coefficient derived from the continuity relation as:

$$
b^{(l)}=1-a_{1}{ }^{(l)}-a_{2}{ }^{(l)}-a_{3}{ }^{(l)}-\cdots-a_{p}{ }^{(l)},
$$

$\lambda$ is a unit conversion factor for instance if $r$ and $q$ are expressed by unit of $\left(\mathrm{mm} \mathrm{h}^{-1}\right)$ and $\left(\mathrm{m}^{3} \mathrm{~s}^{-1}\right)$ respectively, then $\lambda=A / 3.6\left(A\right.$ is catchment area in $\left.\mathrm{km}^{2}\right)$ and $\varepsilon_{l}^{(l)}$ is a noise.

If the AR coefficients $a_{1}{ }^{(l)}$ have been determined, the time series of effective rainfall for each flow component $\hat{r}_{i^{\prime}}^{(l)}$ may be estimated by rearrangement of Equation (12) as follows:

$$
\hat{r}_{i^{\prime}}^{(l)}=\frac{1}{\lambda b^{(l)}}\left(a_{i}^{(l)}-a_{1}^{(l)} q_{i-1}^{(l)}-a_{2}{ }^{(l)} q_{i-2}^{(l)}-\cdots-a_{p}{ }^{(l)} q_{i-p}^{(l)}+\varepsilon_{i}^{(l)}\right) .
$$

When the level of the estimated values of $\hat{r}_{i^{\prime}}^{(l)}$ decreases to the order of error and fluctuates around zero, taking both positive and negative values, the estimated values are considered to be an error $\varepsilon_{i}^{(l)}$ and are then discarded.

The inversely estimated (effective) rainfall time series of the direct flow component $\left(\hat{r}_{i^{\prime}}^{(l)} ; i^{\prime}=i-i_{0}\right)$ are then used as an input of the SFM. In this case, the starting point of the inversely estimated rainfall time series have to be moved backward $i_{0}$ to account the delay time of the rainfall-runoff process (Hino and Hasebe, 1985). The $i_{0}$ value may be determined by comparing the rainfall pattern of the estimated and the observed rainfall time series. 


\section{DATA USED}

Six catchments from two different regions i.e. tropical and temperate regions with area ranging from 34 to $772 \mathrm{~km}^{2}$ are used for the study. Three catchments are located at West Java, Java Island, Indonesia and other three catchments are located at eastern New South Wales (NSW), Australia.

In case of Indonesian data, the discharge and rainfall data were obtained from the Water Resources Engineering Research and Development Center, Bandung, Indonesia. In general, the rainfall data available is short and missing data are frequently found in the rainfall data series. Spatial distribution of rainfall in these areas, as located in tropical region, is quite large.

For Australian data, the hourly rainfall and runoff data were extracted from Pinneena version 6.1 published by the Department of land and Water Conservation, NSW, Australia (1999). The rainfall data for each catchment are obtained from one rainfall station only located at downstream of the catchment near the gauging station. The catchment characteristics and the flood data used for the study are summarized in Table 1.

Table 1. Catchment characteristics and their selected flood events

\begin{tabular}{lccc}
\hline \multicolumn{1}{c}{ Station } & $\begin{array}{c}\text { Catchment } \\
\text { area } \\
\left(\mathrm{km}^{2}\right)\end{array}$ & $\begin{array}{c}\text { Flood events } \\
\text { (y.m.d) }\end{array}$ & $\begin{array}{c}\text { Flood peak } \\
\text { ratio } \\
\left(\mathrm{m}^{3} / \mathrm{s} / \mathrm{km}^{2}\right)\end{array}$ \\
\hline Oxley River at Eungella & 213 & 91.12 .12 & 3.446 \\
Bielsdown Creek at Dorrigo & 82 & 99.03 .02 & 2.232 \\
Nymbodia River at Timmsvale & 34 & 81.05 .21 & 3.773 \\
Cimanuk River at Bojongloa & 183 & 78.05 .04 & 0.691 \\
Cimanuk River at Leuwigoong & 772 & 84.04 .08 & 0.717 \\
Cipeles River at Sukatali & 286 & 94.03 .10 & 1.372 \\
\hline
\end{tabular}

\section{RESULTS AND DISCUSSION}

The performance of the SFM in simulating flood hydrographs based on inversely estimated rainfall and observed rainfall data for all catchments studied is shown in Fig. 1 to Fig. 6. The figures clearly show that for all flood studies, the inversely estimated rainfall could be used for estimating the SFM parameters with satisfactory results even it gives better results in simulating flood hydrograph than the observed one. For Australian. data, the less accurate results may occur due to poor quality of rainfall data used in which the observed rainfall comes from one rainfall station only located at downstream of the catchment. As a result, the rainfall data does not represent the actual catchment rainfall as indicated by poor relation between rainfall and runoff as shown in Fig. 1 to Fig. 3 . On the other hand, the estimated rainfall could represent the catchment rainfall much better than the observed one since the estimated rainfall was derived based on the output of the catchment i.e. runoff only which reflects all phenomena that might be happened in the catchment.

The optimum parameters of the SFM model derived based on the inversely estimated 

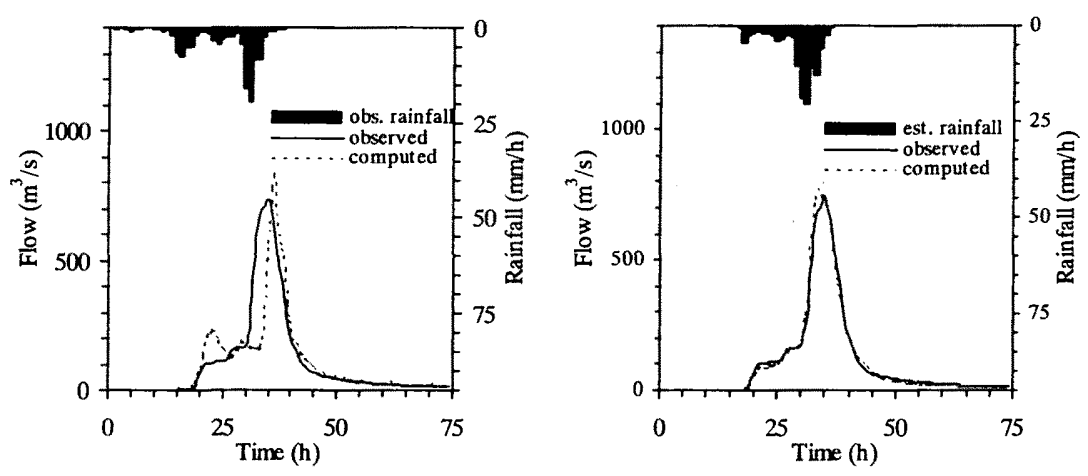

Fig. 1. Comparison between observed and computed flows for Oxley River at Eungella by using observed and estimated rainfall data.
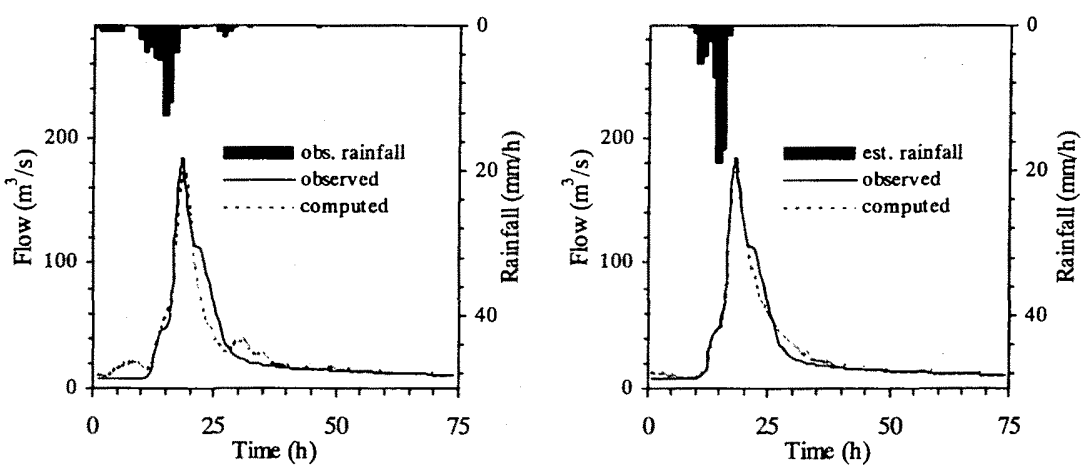

Fig. 2. Comparison between observed and computed flows for Bielsdown Creek at Dorrigo by using observed and estimated rainfall data.
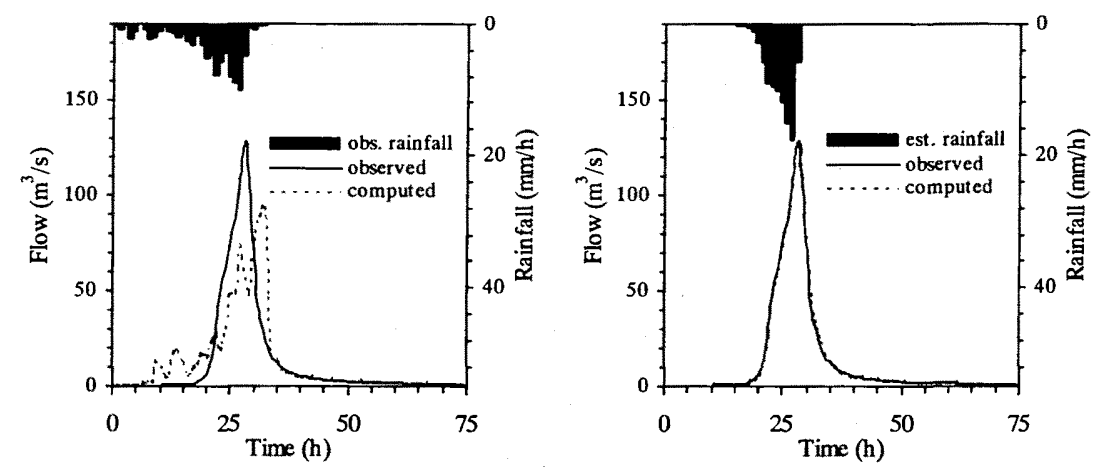

Fig. 3. Comparison between observed and computed flows for Nymbodia River at Timmsvale by using observed and estimated rainfall data. 

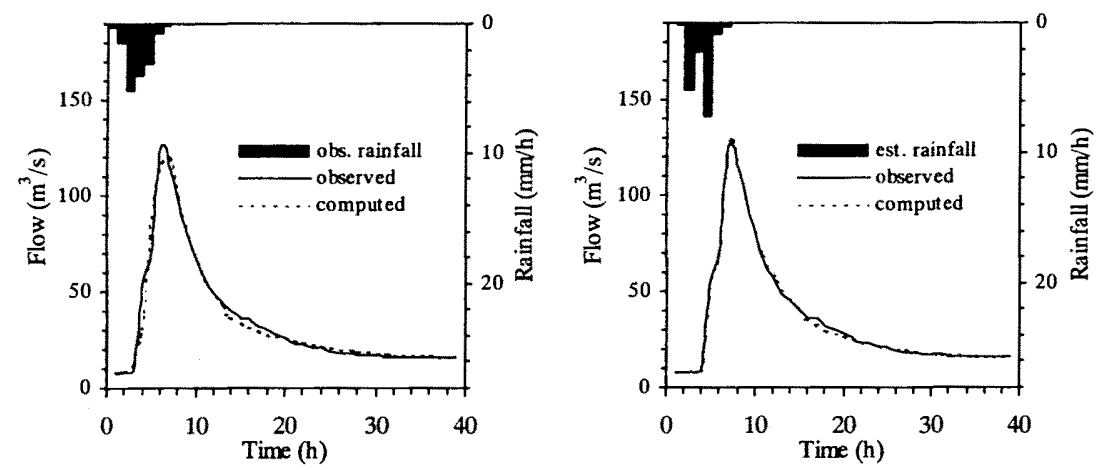

Fig. 4. Comparison between observed and computed flows for Cimanuk River at Bojongloa by using observed and estimated rainfall data.
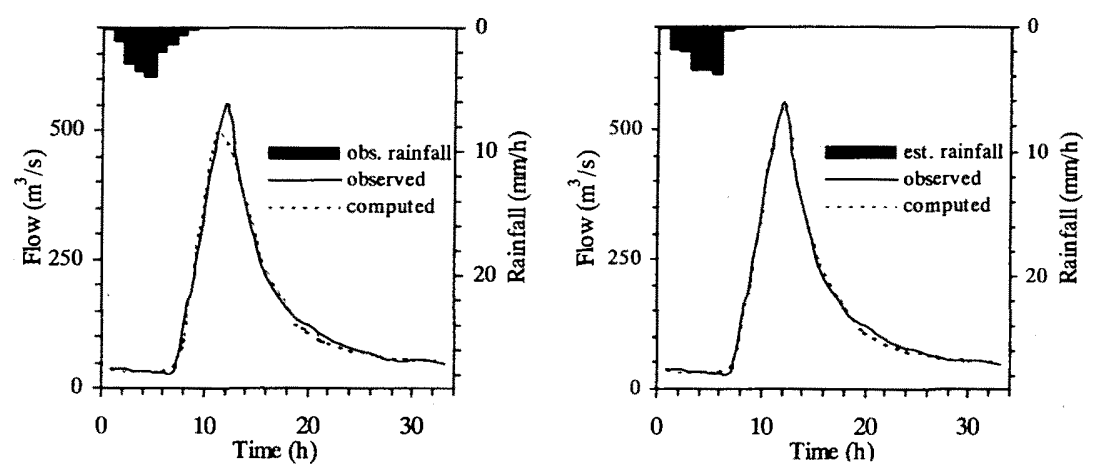

Fig. 5. Comparison between observed and computed flows for Cimanuk River at Leuwigoong by using observed and estimated rainfall data.
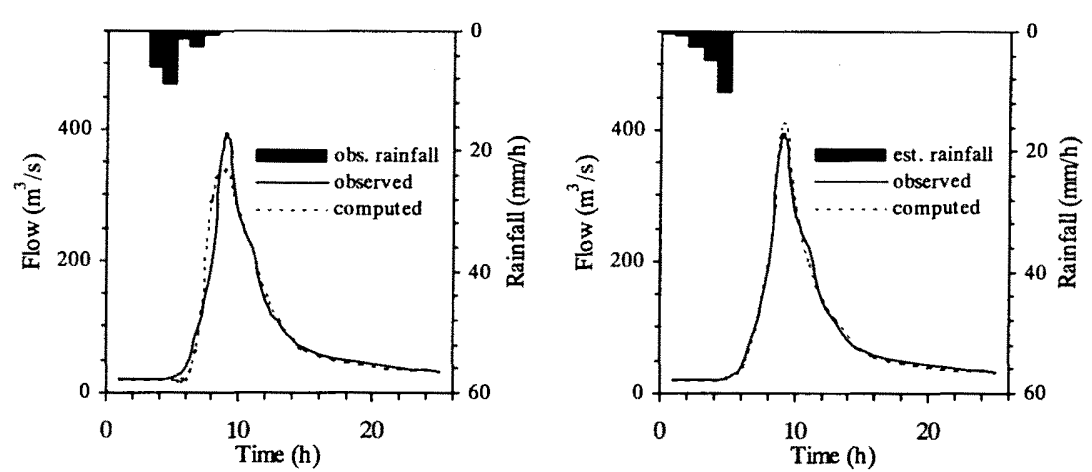

Fig. 6. Comparison between observed and computed flows for Cipeles River at Sukatali by using observed and estimated rainfall data. 
rainfall and observed rainfall data together with the prediction accuracy are presented in Table 2 and Table 3, respectively. Those tables show that the model parameters are quite similar regardless the rainfall type used especially for Indonesian catchments. It means that the filter separation autoregressive method can produce an estimated (effective) rainfall time series with satisfactory results.

Table 2. Resulted SFM parameters based on observed rainfall

\begin{tabular}{|c|c|c|c|c|c|c|c|}
\hline \multirow[b]{2}{*}{ Station } & \multirow{2}{*}{$\begin{array}{l}\text { Flood } \\
\text { events } \\
\text { (y.m.d) }\end{array}$} & \multirow{2}{*}{$\begin{array}{l}\text { Flood peak } \\
\text { ratio } \\
\left(\mathrm{m}^{3} / \mathrm{s} / \mathrm{km}^{2}\right)\end{array}$} & \multicolumn{2}{|c|}{ SFM parameters } & \multicolumn{3}{|c|}{ Prediction accuracy } \\
\hline & & & $K\left(\alpha_{k}, c_{k}\right)$ & $P\left(\alpha_{p}, c_{p}\right)$ & $T_{i}\left(\alpha_{r_{i}}, c_{\tau_{i}}\right)$ & $R E_{\mu}(\%)$ & $R M E(\%)$ \\
\hline Oxley River at Eungella & 91.12 .12 & 3.446 & $(12.7,8.3)$ & $(0.390,0.000)$ & $(4.7,0.6)$ & 13.70 & 32.38 \\
\hline Bielsdown Creek at Dorrig & 99.03 .02 & 2.232 & $(3.5,0.1)$ & $(0.865,0.000)$ & $(2.5,0.1)$ & 5.63 & 9.99 \\
\hline Nymbodia River at Timmsvale & 81.05 .21 & 3.773 & $(6.6,4.5)$ & $(0.135,0.000)$ & $(4.9,1.8)$ & 26.87 & 51.64 \\
\hline Cimanuk River at Bojongloa & 78.05 .04 & 0.691 & $(4.7,0.1)$ & $(0.806,0.000)$ & $(1.6,0.3)$ & 5.78 & 6.71 \\
\hline Cimanuk River at Leuwigoong & 84.04 .08 & 0.717 & $(4.3,0.0)$ & $(0.831,0.110)$ & $(5.8,0.2)$ & 10.70 & 4.73 \\
\hline Cipeles River at Sukatali & 94.03 .10 & 1.372 & $(3.2,0.2)$ & $(0.751,0.041)$ & $(3.4,0.2)$ & 14.57 & 7.80 \\
\hline
\end{tabular}

Table 3. Resulted SFM parameters based on inversely estimated rainfall

\begin{tabular}{|c|c|c|c|c|c|c|c|}
\hline \multirow[b]{2}{*}{ Station } & \multirow{2}{*}{$\begin{array}{l}\text { Flood } \\
\text { events } \\
\text { (y.m.d) }\end{array}$} & \multirow{2}{*}{$\begin{array}{c}\text { Flood peak } \\
\text { ratio } \\
\left(\mathrm{m}^{3} / \mathrm{s} / \mathrm{km}^{2}\right)\end{array}$} & \multicolumn{2}{|c|}{ SFM parameters } & \multicolumn{3}{|c|}{ Prediction accuracy } \\
\hline & & & $K\left(\alpha_{k}, c_{k}\right)$ & $P\left(\alpha_{p}, c_{p}\right)$ & $T_{l}\left(\alpha_{T_{i}}, c_{T_{i}}\right)$ & $R E_{p}(\%)$ & $R M E(\%)$ \\
\hline Oxley River at Eungella & 91.12 .12 & 3.446 & $(5.3,1.2)$ & $(0.811,0.000)$ & $(1.8,0.0)$ & 4.22 & 8.68 \\
\hline Bielsdown Creek at Dorrigo & 99.03 .02 & 2.232 & $(5.0,0.4)$ & $(0.967,0.025)$ & $(1.9,0.0)$ & 0.63 & 6.03 \\
\hline Nymbodia River at Timmsvale & 81.05 .21 & 3.773 & $(2.7,0.1)$ & $(0.940,0.002)$ & $(1.0,0.0)$ & 0.48 & 2.56 \\
\hline Cimanuk River at Bojongloa & 78.05 .04 & 0.691 & $(4.5,0.0)$ & $(0.975,0.056)$ & $(2.0,0.0)$ & 1.05 & 2.34 \\
\hline Cimanuk River at Leuwigoong & 84.04 .08 & 0.717 & $(4.3,0.1)$ & $(0.871,0.000)$ & $(5.9,0.1)$ & 0.34 & 3.48 \\
\hline Cipeles River at Sukatali & 94.03 .10 & 1.372 & $(3.2,0.3)$ & $(0.874,0.034)$ & $(3.9,0.0)$ & 4.98 & 3.11 \\
\hline
\end{tabular}
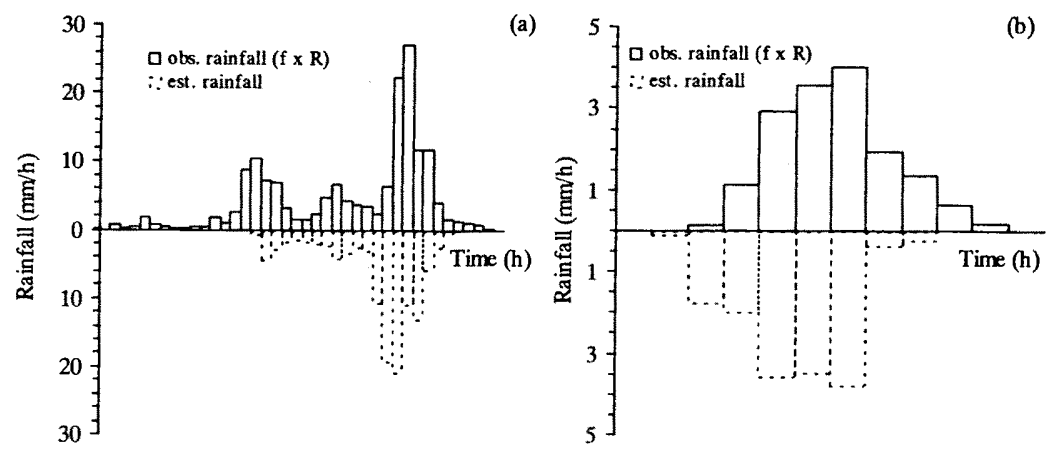

Fig. 7. Comparison between observed and estimated effective rainfall at (a) Oxley River at Eungella and (b) Cimanuk River at Leuwigoong. 
Comparison of the inversely estimated (effective) rainfall obtained using the filter separation autoregressive method and effective observed rainfall $(f \times R)$, in which $f$ and $R$ are runoff coefficient and rainfall data respectively, are given in Fig. 7. The figure indicates that the estimated rainfall compares well with the observed ones. However, the delay time that usually occurs in rainfall-runoff process has to be estimated separately, since the inversely estimated rainfall time series are computed based on the autoregressive values and the flow component only as expressed in Equation (14). Accordingly, the delay time have to be estimated carefully before using the estimated rainfall as an input of rainfall-runoff models, since the delay time will affect the parameter $T_{l}$ of the SFM.

\section{CONCLUSION}

The filter separation autoregressive method is found to be useful for rainfall time series estimation needed for deriving the rainfall-runoff model parameters in catchments where a good quality and quantity of observed rainfall data are not available. The method can produce estimated (effective) rainfall time series with good results and comparable with the observed ones. Since the delay time that usually occurs in rainfall-runoff process has not taken into account in the inverse rainfall estimation method, the delay time have to be estimated carefully before using the estimated rainfall as an input of rainfall-runoff models.

Application of the inversely estimated rainfall as an input of the rainfall-runoff model shows that the inversely estimated rainfall was useful for estimating the rainfall-runoff model parameters both in tropical and in temperate regions. Moreover, the model parameters derived based on the estimated rainfall gives better results in simulating flood hydrographs than based on observed data. Further application to other catchments with a number of flood events is needed to give more idea in relation with the characteristics of the inversely estimated rainfall and its application.

\section{REFERENCES}

Department of Land and Water Conservation 1999 Pinneena 6.1. Department of Land and Water Conservation, New South Wales, Australia.

Hino, M 1986 Improvements in the inversely estimation method of effective rainfall from runoff. Joumal of Hydrology, 83: 137-147

Hino, M. and M. Hasebe 1981 Analysis of hydrologic characteristics from runoff data- a hydrologic inversely problem. Journal of Hydrology, $\mathbf{4 9}: 287-313$

Hino, M. and M. Hasebe 1984 Identification and prediction of nonlinear hydrologic systems by the filter-separation autoregressive (AR) method: extension to hourly hydrologic data. Journal of Hydrology, 68: 181-120

Hino, M. and M. Hasebe 1985 Hydrological Runoff Analysis. Morikita Syuppan, Tokyo, pp. $99-107$ (in Japanese).

Kimura, T. 1961 The flood munoff analysis method by the storage function model. The Public Works Research Institute, Ministry of Construction (in Japanese).

Shikasho, S., Y. Tohara and K. Hiramatsu 1992 Parameter identification of runoff model using fuzzy regression model. Applied Hydrology, 4: 5-12 (in Japanese).

Sugiyama, H., M. Kadoya, A. Nagai and K. Lansey 1997 Evaluation of the storage function model parameter characteristics. Journal of Hydrology, 191: 332-348

Sugiyama, H., M. Kadoya, A. Nagai and K. Lansey 1999 Verification and application of regional equations 
for the storage function runoff model. Journal of The American Water Resources Association, $\mathbf{3 5}$ : 1147-1157

Sujono, J., S. Shikasho and K. Hiramatsu 2001 Hydrograph recession analysis using wavelet transforms. Journal of Fac. Agr., Kyushu University, 45: 557-564

Tanaka, H., S. Uejima and K. Asai 1982 Linear regression analysis with fuzzy model. IEEE Trans. Syst. Man Cybernet, SMC-12: 903-907 